\title{
TESTS OF INFLUENCE OF GEOMETRY AND ELASTICITY OF HOSES OF HYDRAULIC ARTICULATED STEERING SYSTEM ON ITS STIFFNESS
}

\begin{abstract}
A. Skurjat*
Abstract: The maximum speed of articulated vehicles (e.g. wheeled loaders) is limited due to the negative phenomenon of snaking. The snaking occurs, among others, because of the low hydrostatic stiffness of the steering system caused by the elasticity of the hydraulic hoses and the elasticity of the working fluid. The results show the influence of steering geometry on its torsional stiffness and the dependencies allowing to calculate its expected value.
\end{abstract}

Keywords: snaking, articulated steering system, geometry, stiffness

\section{Introduction}

Articulated work vehicles constitute a large group of working machines eagerly used in almost all branches of industry. They are characterized by considerable maneuverability, the ability to generate significant pulling forces, capacity, cheap and easy-to-implement activities related to their servicing and repairs. Unfortunately, they have a number of disadvantages that limit their further development. These are, e.g. the limited possibility of working on substrates with significant inclinations, which may result in their tip over, galloping manifested by longitudinal swaying of the vehicle, lateral swaying and low maximum speed of their movement. Further development of vehicles can be made only as a result of their improvement through the use of supporting systems in the operator's work. Systems preventing their tip over can be found in (Dudziński, 2015, Kosiara, 2017, Sierzputowski, 2015) while preventing galloping in (Kosiara, 2011). The literature on the subject includes very few publications on the phenomenon of snaking of work vehicles, i.e. those that mainly moving along off-roads. However, they can be specified in (Skurjat, 2015, Dudziński, 2006). The phenomenon of snaking is defined here as the sinusoidal trajectory of the selected point of the vehicle having a certain amplitude and frequency measured in relation to the assumed direction of movement. The amplitude and frequency of occurrence depends on a man, both external and internal factors (Skurjat, 2015) and in particular on the hydrostatic stiffness of the turning system.

Steering stiffness calculations presented in the paper (Azad, 2006) are performed by use of numerical formulas only. There are no experimental measurements on a real object to compare obtained values. In their work stability criterion is proposed and different tests and results are presented. Proposal for mitigating snaking phenomenon by locking differentials is presented in (Azad, 2007).

A crucial problem encountered while calculating the stiffness of hydraulic system is to describe precise oil bulk modulus as a function of aeration and pressure. Many non-accurate formulas (at low-pressure region) can be found in the literature. In work (Gholizadeh, 2013) the author compares known bulk modulus numerical calculating methods with experimental results. There is also a new proposal for oil elasticity calculation.

Aleksander Skurjat, Ph. D., associate professor, The Departament of Off-Road Machine and Vehicle Engineering, Mechanical Departament, Wroclaw University of Science and Technology, I. Lukasiewicza 7/9, 50-371, Wrocław aleksander.skurjat@pwr.edu.pl 
The total stiffness of the steering system depends, among other things, on the elastic modulus of the hydraulic oil (its aeration), the flexibility of the walls of the hydraulic hoses (length and type of the carcass) as well as on the arrangement of the cylinders (geometry) of the steering system. Numerous studies have shown that even small changes in the total internal volume of the hydraulic system have a significant effect on changes in the steering angle. The reason for this lies in the fact that hydraulic cylinders with short stroke are usually used, hence even small changes in the position of the cylinder piston significantly affect the angular position of the front and rear frames and of the turn as a result.

\section{Methods}

Manufacturers of vehicles with articulated steering systems use different geometries for the cylinders. They are characterized by different torsional stiffness. Fig. 1 shows the symbols of stiffness of the steering system adopted for calculation.

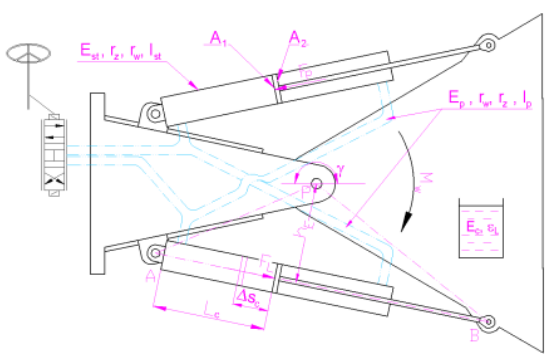

Fig. 1: Description of the geometry and parameters used to determine the stiffness of the articulated vehicle's steering system

Stiffness of the steering system can be determined from the dependencies presented in Tab. 1 .

Tab. 1: Dependencies to determine the stiffness of the steering system

Stiffness of the steering system $\quad k_{\gamma}=\frac{\Delta M_{s}}{\Delta \gamma_{s}}$

Change of the steering angle due to

changes in the piston position of the

hydraulic cylinder $\Delta \mathrm{s}_{\mathrm{c}}$

$$
\Delta \gamma_{s}=\gamma_{0}-\gamma_{1}
$$

Repositioning of the hydraulic cylinder piston $\Delta_{\mathrm{s}}$

$$
\Delta s_{c}=\Delta s_{s}+\Delta s_{p}+\Delta s_{p, E, i}
$$

Dependence determining the change in the elastic modulus of liquids as a result of aerating the liquid

$$
E_{c r}=\frac{\left(\left(1-\varepsilon_{l}\right)+\varepsilon_{l}\left(\frac{P_{o}}{p_{w}}\right)^{1 / n}\right)}{\frac{\varepsilon_{l}}{n p_{w}}\left(\frac{P_{o}}{p_{w}}\right)^{1 / n}+\frac{1-\varepsilon_{l}}{E_{c}}}
$$

Change in liquid volume due to the compressibility of the liquid inside the cylinders

$$
\Delta V_{s}=\frac{V_{s} p_{w}}{E_{c r}}
$$

Cylinder stroke as a result of $\Delta \mathrm{V}_{\mathrm{s}}$

$$
\Delta s_{s}=\frac{\Delta V_{s}}{\left(A_{1}+A_{2}\right)}
$$

Change in liquid volume due to compressibility of liquid inside hydraulic hoses

$$
\Delta s_{p}=\frac{\sum_{i}^{n} V_{p, i} p_{w}}{E_{c r}\left(A_{1}+A_{2}\right)}
$$

Change in liquid volume due to expansion of hydraulic hoses

$$
\Delta \mathrm{V}_{\mathrm{pE}, \mathrm{i}}=\frac{p_{w} \sum_{i}^{n} V_{p, i}}{E_{p, i}}
$$

Stroke of cylinder as a result of $\Delta \mathrm{V}_{\mathrm{pEi}}$

$$
\Delta s_{p, E, i}=\frac{\Delta V_{s}}{\left(A_{1}+A_{2}\right)}
$$


where: $\varepsilon_{\mathrm{L}}-$ the ratio of the volume of undissolved gas to the volume of liquid [-];

$\mathrm{E}_{\mathrm{c}}-$ modulus of elasticity of non-aerated oil [Pa],

$\mathrm{P}_{0}$-atmospheric pressure $[\mathrm{Pa}]$

$\mathrm{n}$ - polytropic exponent [-]

$\Delta \mathrm{M}_{\mathrm{s}}[\mathrm{Nm}]$ - torsional moment; $\Delta \gamma_{\mathrm{s}}[\mathrm{rad}]$ - change of articulation angle

The purpose of the following analysis is to determine the geometry where the steering system achieves the highest stiffness. Fig. 2 presents 9 tested solutions were presented. $P$ is the axis of rotation of the front and rear frames, $\mathrm{AP}$ and $\mathrm{BP}$ are the distances between the articulated steering $(\mathrm{P})$ and the mounting point of the hydraulic cylinder (A and B).
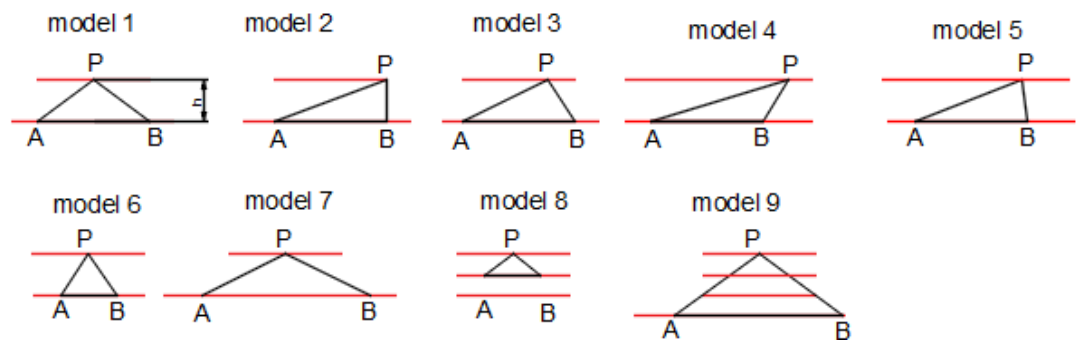

Fig. 2: Tested steering system geometries, AP, BP - distance of the steering cylinder's lug to articulated steering axis, $A B$ - length of the hydraulic cylinder

The models 1-5 differ in the lengths of the sides AP and BP while maintaining the same length of the AB cylinder and the same internal volume of the steering system. Models 1-7 retain the same height of the triangle APB, i.e. the arm of the force he. In models 6 and 7 the length of the AB cylinder has been changed, maintaining the geometry of the isosceles triangle. In models 8 and 9, the angle between the arms of the triangle $\mathrm{AP}$ and $\mathrm{PB}$ and its isoscelescity were maintained, affecting the length $\mathrm{AB}$ (cylinder) and its height. Due to small changes in the steering angle between the vehicle units, equal force arms of cylinders are assumed on both sides of the vehicle.The tests are conducted using the above equations. Stiffness of the steering system $\mathrm{k}_{\gamma}$ has been determined for a constant value of the forcing moment $\mathrm{M}_{\mathrm{w}}$. The basic parameters adopted for calculations are presented in tab. 2 .

Tab. 2: Parameter values adopted for calculations

\begin{tabular}{ll}
\hline Forcing moment & $\mathrm{Mw}=8500 \mathrm{Nm}$ \\
\hline Diameter of piston Ds/ piston rod ds & $\mathrm{Ds}=0.1 / \mathrm{ds}=0.05 \mathrm{~m}$ \\
\hline $\begin{array}{l}\text { Cylinder length for model 1-5, changes for other } \\
\text { models in the text }\end{array}$ & $\mathrm{AB}=0.98 \mathrm{~m}$ \\
\hline Non-aerated working liquid modulus & $\mathrm{Ec}=16 \mathrm{MPa}$ \\
\hline The gas content in the working liquid & $\varepsilon \mathrm{l}=0.02[-]$ \\
\hline Diameter of the hose dp1/ Length of the hose lp1 & $\mathrm{dp} 1=16 \mathrm{~mm} \mathrm{lp} 1=5 . \mathrm{m}$ \\
\hline Diameter of the hose dp2/ Length of the hose lp2 & $\mathrm{Dp} 2=20 \mathrm{~mm} \mathrm{lp} 2=2 \mathrm{~m}$ \\
\hline Hose modulus of elasticity Ep,1/2 & Ep, $1=1500 / 1500 \mathrm{MPa}$ \\
\hline
\end{tabular}

\section{Conclusions}

As expected - Fig. 3 geometries of models 1-5 have obtained the same steering stiffness. This is due to maintaining the same volume of liquid in the hydraulic system (solid AB) and the fact that the same force arms were maintained (the height of the triangle of the cylinders' construction he), that is the same pressure values (from load) in the cylinder chambers. These systems differ in their performance when steering.

Model 6 in relation to models 1-5 is characterized by $50 \%$ reduced the length of the AB cylinder. Reducing the amount of liquid has increased stiffness by approx. 38\%. On the other hand, the model 7 with 1.5 times increase of the length of the $\mathrm{AB}$ cylinder compared to the models 1-5 results in a 33\% decrease in stiffness. It shows that the change in steering stiffness is a non-linear phenomenon, despite the fact that the length change of the cylinder linearly influences the internal volume change. 
Decreasing the arm force he by $50 \%$ in the model 8 , brought a stiffness decrease by approx. $60 \%$, while an increase in the length of the arm by $30 \%$ resulted in an increase in stiffness by $60 \%$. It shows that the spacing of the steering cylinders is of great importance. Even a small moment created by the hydraulic system and opposing external force allows for high stiffness. One should also pay attention to the changes of elasticity modulus $\mathrm{E}_{\mathrm{cr}}$ of working liquid. It takes the value the higher the higher is the pressure $\mathrm{p}_{\mathrm{w}}$ in the system. The increase of arm $h_{e}$ results in the decrease of internal pressure in $p_{w}$ with this forcing moment $\mathbf{M}_{\mathrm{w}}$. The stiffness of the steering system depends on many factors and the geometrical parameters / cylinder spacing play a significant role.
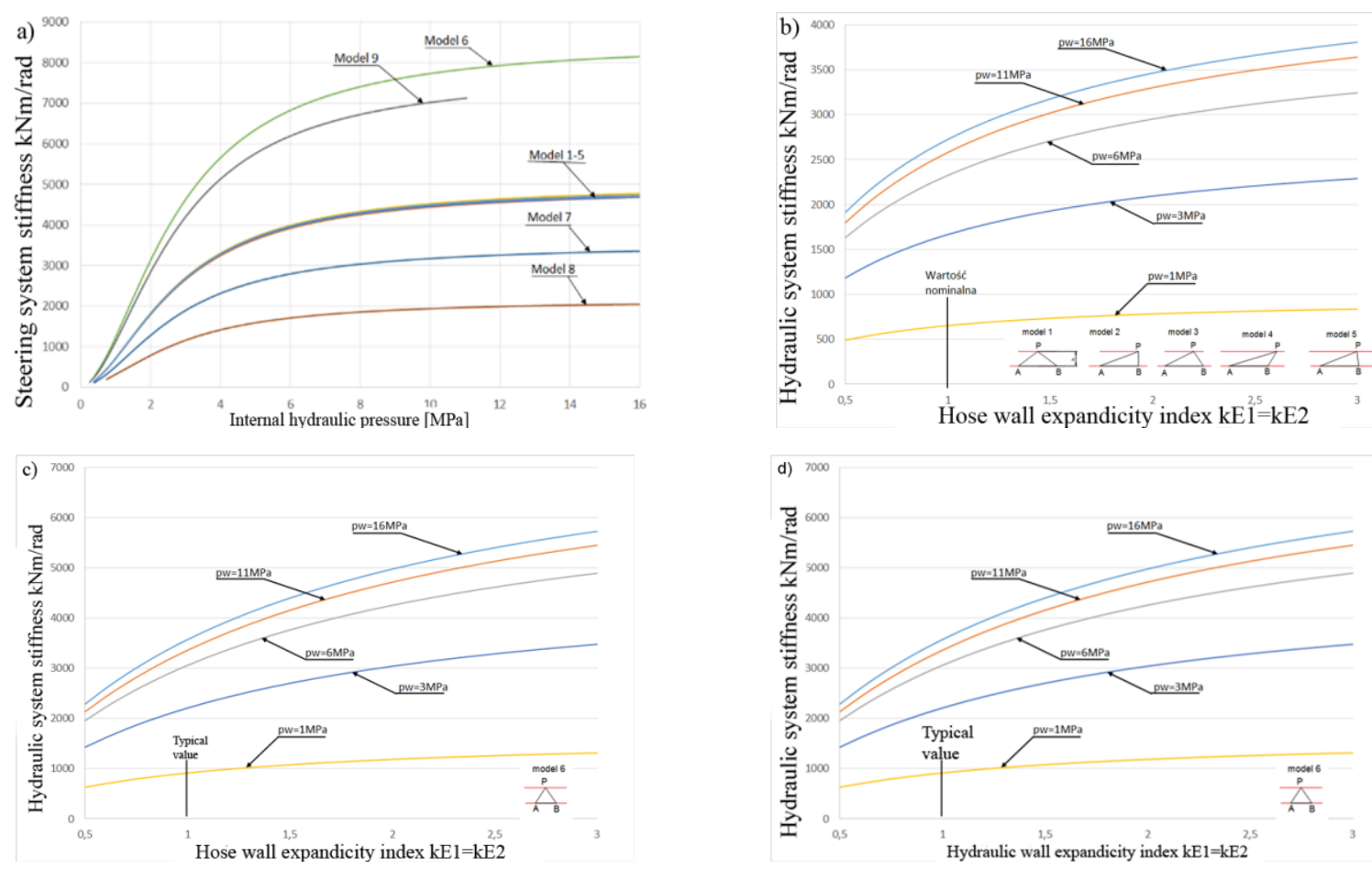

Fig. 3: : a) results of the geometry impact test on stiffness of the steering system, b) results of the geometry 1-5 impact test on stiffness of the steering system for different values $k E 1=k E 2$, c) results of the geometry 6 impact test on stiffness of the steering system for different $k E 1$ values $=k E 2, d)$ results of the geometry 6 impact test on stiffness of the steering system

\section{References}

Azad, N. L. (2006) Dynamic Modelling and Stability Controller Development for Articulated Steer Vehicles, Ph. D. Thessis, Waterloo, Ontario, Canada

Azad, N.L. and Khajepour, A. and McPhee, J. (2007) Effects of locking differentials on the snaking behavior of articulated steer vehicles, International Journal of Vehicle Systems Modelling and Testing, Vol. 2, No. 2.

Dudziński, P. and Hapel, G. and Skurjat, A. (2009) Method and a control device for automatic and adaptative steering of a vehicle, patent pending, PL nr 388851.

Dudziński, P. and Kosiara, A. (2015) Influence of tire and ground stiffness on articulated wheeled earth-moving machine's tip-over stability, Transport Przemysłowy i Maszyny Robocze, nr 2, s. 39-47.

Dudziński, P. (2006) Lenksysteme für Nutzfahrzeuge, Springer-Verlag

Gholizadeh, H. (2013) Modeling and Experimental Evaluation of the Effective Bulk Modulus for a Mixture of Hydraulic Oil and Air, Ph. D. Thessis, University of Saskatchewan Saskatoon

Kosiara, A. (2017) Evaluation of usability of different parameters in estimation of the rollover stability of a single bucket tracked excavator, Autobusy, nr 6, s. 810-815.

Kosiara. A. (2011) Analysis of wheel loaders longitudinal oscillations reduction possibility by using passive stabilizers, Napędy i Sterowanie, R. 13, nr 1, s. 92-95.

Sierzputowski, G. (2015) Simulation studies of the impact of the oscillating axle on the tipping stability of articulated wheeled vehicles while driving, Kraków, Creativetime.

Skurjat, A. and Serwatka, K. (2015) Examining the possibility of eliminating snaking behaviour by braking vehicles wheels, Logistics, 2015, nr 5, s. 1363-1370. 